\title{
EVASÃO ESCOLAR NA EDUCAÇÃO DE JOVENS E ADULTOS: UM ESTUDO NA REDE ESTADUAL DE ENSINO DE PERNAMBUCO
}

\author{
Suzane Bezerra de França ${ }^{1}$ \\ Daniela Pedrosa de Souza ${ }^{2}$
}

\section{RESUMO}

A evasão escolar constitui um dos maiores problemas para as redes de ensino, em diferentes níveis e modalidades. O tratamento da problemática da evasão, no contexto da Educação de Jovens e Adultos, exige uma abordagem particularizada, tendo em vista que a própria modalidade existe como resultado desse fenômeno. Neste sentido, buscamos neste trabalho investigar os aspectos que influenciam a ocorrência da evasão escolar na EJA, no âmbito da Rede Estadual de Ensino de Pernambuco. O enfoque do estudo esteve voltado para compreender a questão a partir dos olhares de estudantes, professores e gestores escolares. Os participantes do estudo indicaram que a evasão escolar dos estudantes da EJA ocorre, principalmente, em decorrência de aspectos externos às escolas. Os dados também apontaram que a permanência pode ser impactada por ações didáticas, que promovam o fortalecimento e a visibilidade da EJA na comunidade escolar.

Palavras-chave: Educação de Jovens e Adultos. Evasão Escolar. Direito à Educação. Permanência na Escola.

\footnotetext{
${ }^{1}$ Doutora em Ensino de Ciências e Matemática. Professora da Universidade de Pernambuco - UPE/Campus Mata Norte e do Programa de Pós-Graduação em Educação da Universidade Federal de Pernambuco, na linha de pesquisa Educação em Ciências. ORCID: https://orcid.org/0000-0003-3642-9717. E-mail: suzane.franca@upe.br.

${ }^{2}$ Mestre em Biologia Animal pela Universidade Federal de Pernambuco - UFPE. Professora técnica na Gerência de Políticas Educacionais de Jovens Adultos e Idosos - Secretaria de Educação e Esportes de Pernambuco. ORCID: https://orcid.org/0000-0002-3475-0809. Email: danipedrosa82@gmail.com
} 


\section{STUDENT DROPOUT IN THE YOUTH AND ADULT EDUCATION: A STUDY IN THE PUBLIC SCHOOL SYSTEM OF PERNAMBUCO}

\section{ABSTRACT}

Student dropout is one of the biggest problems for teaching networks at different levels and modalities. The treatment of the problem of student dropout in the context of Youth and Adult Education (YAE) requires a particularized approach because the modality itself exists as a result of this phenomenon. In this sense, we seek to investigate the aspects that influence the occurrence of student dropout in the YAE within the public school system of the state of Pernambuco. The focus of the study was to understand the issue from the perspectives of students, teachers and school managers. The study participants indicated that student dropout of YAE students occurs due to external aspects of schools. The data indicated that permanence can be impacted by didactic actions that promote the strengthening and visibility of YAE in school community.

Keywords: Youth and Adult Education. Student Dropout. Right to Education. Stay in School.

\section{DESERCIÓN ESCOLAR EN LA EDUCACIÓN DE JÓVENES Y ADULTOS: UN ESTUDIO EN LA RED PÚBLICA DE ENSEÑANZA DE PERNAMBUCO}

\section{RESUMEN}

La deserción escolar es uno de los mayores problemas en las redes de enseñanza en diferentes niveles y modalidades. El tratamiento del problema de la deserción escolar en el contexto de la Educación de Jóvenes yAdultos (EJA) requiere un enfoque particularizado porque la modalidad en sí existe como resultado de este fenómeno. En este sentido, buscamos investigar los aspectos que influyen en la ocurrencia de la deserción escolar en la EJA en la red pública de enseñanza en el estado de Pernambuco. El enfoque del estudio fue comprender el tema desde las perspectivas de los estudiantes, 
profesores y gestores escolares. Los participantes del estudio indicaron que la deserción escolar de los estudiantes de la EJA se produce debido a aspectos externos de las escuelas. Los datos indicaron que la permanencia puede ser afectado por acciones didácticas que promuevan el fortalecimiento y la visibilidad de la EJA en la comunidad escolar.

Palabras clave: Educación de Jóvenes y Adultos. Deserción Escolar. Derecho a la Educación. Permanencia en la Escuela.

\section{INTRODUÇÃO}

No bojo das pesquisas de educação, é possível observar uma diversidade de estudos que abarcam a temática da evasão escolar. Trata-se de um fenômeno complexo, que ocorre nas instituições de ensino em todos os níveis e modalidades educativas. Entendido como a perda de estudantes, a evasão gera consequências sociais, econômicas e no desenvolvimento das pessoas (BORJA, MARTINS, 2014). Dada a sua complexidade, o tema tem sido objeto de investigações, com vistas a compreender os motivos e os impactos da evasão para vida dos estudantes e dos sistemas de ensino. A questão ganhou relevo entre os pesquisadores a partir das duas últimas décadas, quando a educação passou a ser um direito assegurado a todos pela Constituição Federal Brasileira (BRASIL, 1988), e com a Lei de Diretrizes e Bases da Educação Nacional (Lei 9.394/96) que estabelece, no Art. $4^{\circ}$, o dever do Estado de garantir o Ensino Fundamental obrigatório, a universalização do Ensino Médio e assegurando a gratuidade da oferta em ambas as etapas da educação básica.

Nesse contexto, a evasão escolar constitui um dos maiores problemas para as redes de ensino, designando uma problemática de caráter multidimensional, que envolve aspectos pessoais, sociais e institucionais e, concordamos com Dore et al. (2014), que a evasão escolar não é responsabilidade apenas da escola, mas também da família, das políticas de governo e de toda a comunidade escolar. Assim, argumentamos que o fenômeno da evasão escolar é também 
um diagnóstico de fracasso da própria escola, dos docentes e dos sistemas de ensino.

Na perspectiva de compreender esse fenômeno, Branco et al. (2019) identificaram que a produção acadêmica expressa fatores internos e externos às escolas. Entre os fatores externos à escola encontram-se a relação familiar, as desigualdades sociais, a violência, a necessidade de trabalhar. Em relação aos fatores internos, esses autores apontam a infraestrutura escolar precária, a necessidades de formação dos professores, a inadequação de estratégias didáticas, voltadas ao perfil dos estudantes, a desmotivação dos estudantes, entre outros.

Desse modo, entendemos que o tratamento da problemática da evasão no contexto da Educação de Jovens e Adultos - EJA exige uma abordagem particularizada, tendo em vista que a própria modalidade existe em decorrência desse fenômeno ter sido vivenciado por seus estudantes, ao longo da trajetória escolar. Por esse motivo, a EJA abarca uma diversidade de sujeitos, que não teve acesso à educação ou que tiveram seus percursos escolares interrompidos: mulheres, negros, donas de casa, chefes de família, trabalhadores, agricultores, idosos e também jovens.

Nessa direção, a EJA é reconhecida como uma modalidade de ensino que atende à população que não teve acesso à educação básica ou à possibilidade de continuá-la em idade própria, conforme preceituam os artigos 37 e 38, da Lei Federal no 9.394/1996 (Lei de Diretrizes e Bases da Educação Nacional - LDBEN). A EJA é uma modalidade educativa com características próprias, que tem a educação popular como um pilar teórico-prático, uma vez que a EJA nasceu das lutas da Educação Popular, na perspectiva freireana, na segunda metade do século 20. Neste sentido, as bases epistemológicas da Educação Popular possibilitaram reconhecer e considerar os conhecimentos e saberes prévios dos estudantes, permitindo que o diálogo, a participação, a amorosidade e a criticidade se tornassem balizadores do processo de ensinoaprendizagem libertador e emancipatório.

Para tanto, a EJA enquanto modalidade de ensino que busca enfrentar os processos educacionais excludentes carece de atenção, no sentido de delinear estratégias para garantir a permanência 
daqueles que retornam às escolas. Nesse contexto, o presente estudo partiu da necessidade de construir dados que pudessem subsidiar ações e políticas para o enfrentamento da evasão escolar na EJA, no âmbito da Rede Estadual de Pernambuco.

Por conseguinte, a partir deste estudo, intentamos responder a três questionamentos: Por que os estudantes abandonam a vida escolar na EJA? Por que retornam à escola? Quais motivos contribuem para sua permanência? Neste sentido, buscamos neste trabalho investigar os aspectos que influenciam a ocorrência da evasão escolar na EJA, no âmbito da Rede Estadual de Ensino de Pernambuco. Para isso, inicialmente, foi considerada a necessidade de investigar a questão a partir da ótica dos atores diretamente envolvidos estudantes, professores e gestores escolares - no que se refere aos aspectos que acarretam a evasão de estudantes na modalidade EJA. A investigação se ampara na premissa de que compreender o fenômeno da evasão escolar, é uma forma de contribuir para elaborar ações de promoção à permanência escolar.

\section{METODOLOGIA}

Este estudo apresenta uma abordagem quali-quantitativa, visto que, como afirmam Falcão e Régnier (2000), a quantificação abrange procedimentos que auxiliam o pesquisador a extrair dos dados subsídios para responder as perguntas que o mesmo estabeleceu para o trabalho. Esses autores lembram que os dados quantitativos são recursos para o pesquisador tecer reflexões, não se restringindo unicamente aos aspectos numéricos. Desse modo, o desenho metodológico da pesquisa envolveu a pesquisa exploratória e descritiva. A etapa exploratória foi conduzida no sentido da construção do objeto de estudo, elaboração do quadro teóricometodológico, seleção das unidades escolares e inclusão do perfil dos sujeitos participantes da pesquisa. Os procedimentos realizados nesta etapa foram essenciais para uma aproximação com o objeto de pesquisa, como indicado por Gil (1991). Já na etapa descritiva aconteceu a construção dos dados, por meio de questionários direcionados aos sujeitos participantes do estudo. 
Dessa maneira, o presente trabalho é um recorte de uma pesquisa mais ampla que vem sendo desenvolvida na Rede Estadual de Ensino de Pernambuco, por meio da Gerência de Políticas Educacionais de Jovens, Adultos e Idosos (GEJAl), desde 2014, quando instituiu um grupo de estudos sobre evasão escolar na EJA. Inicialmente, considerou-se que os dados sobre evasão podiam ser obtidos pela diferença entre a matrícula inicial e a matrícula final das turmas de EJA. Contudo, com o aprofundamento dos estudos, constatou-se que a evasão na rede ocorre quando o estudante deixa de se matricular, sem que tenha completado a escolaridade no ano anterior. Ou seja, há evasão quando, no ano seguinte à sua matrícula, o estudante não retorna à Rede, na escola de origem ou em qualquer outra.

Os dados foram construídos de maneira colaborativa com as coordenações da EJA das dezesseis Gerências Regionais da Educação da Rede Estadual, nas seguintes etapas: (1) elaboração dos critérios de escolhas das escolas a serem incluídas na pesquisa; (2) elaboração dos questionários; (3) aplicação dos questionários; (4) sistematização e análise dos dados. Para a seleção das escolas participantes do estudo, foram utilizados os seguintes critérios: município com maior população acima de 25 anos fora da escola e com o maior número de estudantes matriculados na modalidade de acordo com o Sistema da Educação de Pernambuco (PERNAMBUCO, 2017). À vista disso, dezesseis unidades escolares que ofertam a EJA na Rede Estadual de Ensino participaram da pesquisa no ano de 2017 (quadro 1).

A evasão escolar na EJA é um fenômeno complexo que encerra circunstâncias individuais, institucionais e sociais. Segundo Silva Filho e Araújo (2017), a fuga da escola é somente um produto final desse processo. A oferta da EJA pela Rede Estadual se faz mediante as unidades de ensino, que são abarcadas pelas dezesseis Gerências Regionais de Educação, que configuram todo o estado de Pernambuco. Portanto, a matrícula na EJA é facultada a qualquer adolescente, jovem ou adulto que não teve acesso à educação básica em idade própria ou apresenta descontinuidade de estudos por motivos diversos, como orienta o artigo $5^{\circ}$ da Resolução CNE/CEB $n^{\circ}$ 3/2010 (BRASIL, 2010). 
Quadro 1. Escolas participantes da pesquisa sobre evasão escolar na EJA

\begin{tabular}{|l|l|}
\hline \multicolumn{1}{|c|}{ GRE/Municípios } & \multicolumn{1}{|c|}{ Escola } \\
\hline $\begin{array}{l}\text { Sertão do Médio São Francisco } \\
\text { (Petrolina) }\end{array}$ & $\begin{array}{l}\text { Escola Judith Gomes de } \\
\text { Barros }\end{array}$ \\
\hline $\begin{array}{l}\text { Sertão do Araripe (Araripina e e } \\
\text { Ouricuri) }\end{array}$ & Escola São Vicente de Paula \\
\hline Vale do Capibaribe (Limoeiro) & EREM Austro Costa \\
\hline $\begin{array}{l}\text { Sertão do Submédio São Francisco } \\
\text { (Petrolândia e Floresta) }\end{array}$ & Escola Delmiro Gouveia \\
\hline Mata Norte (Carpina) & Escola João Cavalcanti Petribu \\
\hline Mata Sul (Ribeirão) & Escola Pe. Américo Novaes \\
\hline Metropolitana Norte (Olinda) & Escola Cândido Pessoa \\
\hline Recife Sul (Recife) & EREM João Bezerra \\
\hline $\begin{array}{l}\text { Sertão do Moxotó-Ipanema } \\
\text { (Arcoverde e Pesqueira) }\end{array}$ & Escola Professor \\
\hline $\begin{array}{l}\text { Sertão do Alto Pajeú (Afogado da } \\
\text { Ingazeira e Serra Talhada) }\end{array}$ & Escola Solidônio Leite \\
\hline Mata Centro (Gravatá) & Escola Aarão Lins de Andrade \\
\hline Recife Norte (Recife) & Escola Estácio Coimbra \\
\hline $\begin{array}{l}\text { Agreste Meridional (São Bento do } \\
\text { Una e Garanhuns) }\end{array}$ & Escola Elpídio Barbosa Maciel \\
\hline $\begin{array}{l}\text { Sertão Central (São José do } \\
\text { Belmonte e Salgueiro) }\end{array}$ & Escola Napoleão Araújo \\
\hline $\begin{array}{l}\text { Metropolitana Sul (Jaboatão dos } \\
\text { Guararapes) }\end{array}$ & $\begin{array}{l}\text { Escola Desembargador José } \\
\text { Neves Filho }\end{array}$ \\
\hline $\begin{array}{l}\text { Agreste Centro Norte (Santa Cruz do } \\
\text { Capibaribe) }\end{array}$ & Escola Luiz Alves da Silva \\
\hline
\end{tabular}

Fonte: Elaborado pelas autoras, pesquisa (2017). 


\section{OS PARTICIPANTES DO ESTUDO}

Participaram deste estudo 1.333 estudantes, sendo a maior parte do sexo feminino, com faixa etária entre os 20 e 59 anos de idade, matriculada na EJA Médio e exercendo atividades remuneradas. Os estudantes matriculados na EJA ensino Médio representam (85\%), já os estudantes matriculados na EJA Ensino Fundamental totalizam (15\%) dos pesquisados. A maioria dos estudantes trabalha para sustento de si e de sua família, seja de maneira informal (45\%), seja formalizada (14\%), enquanto (40\%) não desenvolve atividade remunerada e (1\%) dos estudantes assinalou a resposta "outros".

Esses dados corroboram com o exposto por Arroyo (2007) quando enfatiza que há pouca oferta de trabalho formal para esses sujeitos, o que acarreta uma parte considerável de estudantes sobrevivendo do trabalho informal e do subemprego.

O grupo de docentes da pesquisa é constituído por 114 participantes, majoritariamente do sexo feminino (55\%), na faixa etária entre 20 e 59 anos de idade (98\%) e com menos de uma década de experiência docente (82\%). Esses docentes atuam na EJA e também no Ensino Fundamental e/ou Médio. O tempo de experiência docente é relevante, já que pode contribuir para tornar esses sujeitos mais aptos a indicarem as razões de abandono e de retorno à escola, uma vez que muitos desses professores participam da vida escolar dos estudantes da EJA, mesmo antes deles ingressarem na modalidade.

O estudo contou também com a participação de 25 profissionais das equipes gestoras, das escolas pesquisadas. A maior parte dos participantes teve experiência docente anterior na modalidade EJA (76\%) e possuem menos de cinco anos de gestão escolar (56\%). A participação da gestão escolar foi imprescindível para compreensão dos registros das matrículas e evasão escolar efetuados nas escolas, na fase inicial da pesquisa. 


\section{A CONSTRUÇÃO DOS DADOS}

Para coleta de dados nas escolas foram desenvolvidas pesquisas documentais, referentes aos dados de matrícula. Partindo disso, foram elaborados questionários direcionados aos três grupos de sujeitos da escola: equipe gestora, corpo docente e discente da modalidade EJA. Em momento posterior, houve uma reunião com os coordenadores de EJA das dezesseis Gerências Regionais de Educação do Estado, para discutir e validar os questionários, bem como a dinâmica da coleta, visando uma construção coletiva e mais assertiva da pesquisa.

Desse modo, os questionários destinados aos estudantes e professores continham onze questões e o destinado aos gestores, doze questões; ambas fechadas, contemplando o perfil dos participantes e os fatores que influenciam tanto a evasão, quanto a permanência na escola. Dessa maneira, os questionários foram aplicados por um profissional de cada uma das dezesseis Regionais, nas unidades escolares, no ambiente das salas de aula, contando com a disponibilidade de uma hora para a leitura compartilhada de todas as questões, a fim de sanar possíveis dúvidas, dos estudantes. Já a coleta de dados da gestão e docentes ocorreu na sala de convivência dos educadores.

Ao final, os dados foram reunidos e possibilitaram inferir pontos de encontro e de afastamento entre os olhares dos três grupos de sujeitos participantes do estudo. Desse modo, os resultados são apresentados em três blocos: as razões para o abandono escolar; as razões para o retorno e as razões para a permanência dos estudantes da EJA, nas escolas.

\section{AS RAZÕES PARA O ABANDONO A PARTIR DE TRÊS OLHARES}

Sobre as razões para o abandono (Gráfico 1), estudantes, docentes e equipes gestoras acreditam ser o trabalho o principal motivo da interrupção dos estudos (49\%), (74\%), (58\%), respectivamente. Como argumentado por Arroyo (2007), as condições sociais dos jovens populares, diante da necessidade diária 
de busca pela sobrevivência, faz com que o projeto de futuro, próprio da escolarização, acabe por não comportar esses estudantes. Mesmo que a modalidade seja direcionada a estudantes trabalhadores, há necessidade de que a escola repense os mecanismos de lidar com as diversas formas de ocupação e sazonalidade, das situações de trabalho vivenciadas por nossos estudantes: ambulantes (vendedores dos mais diversos itens de utilidade), feirantes, trabalhadores da indústria e também do turismo local.

Gráfico 1: Aspectos que influenciam a desistência da vida escolar, na visão de estudantes, docentes e gestores

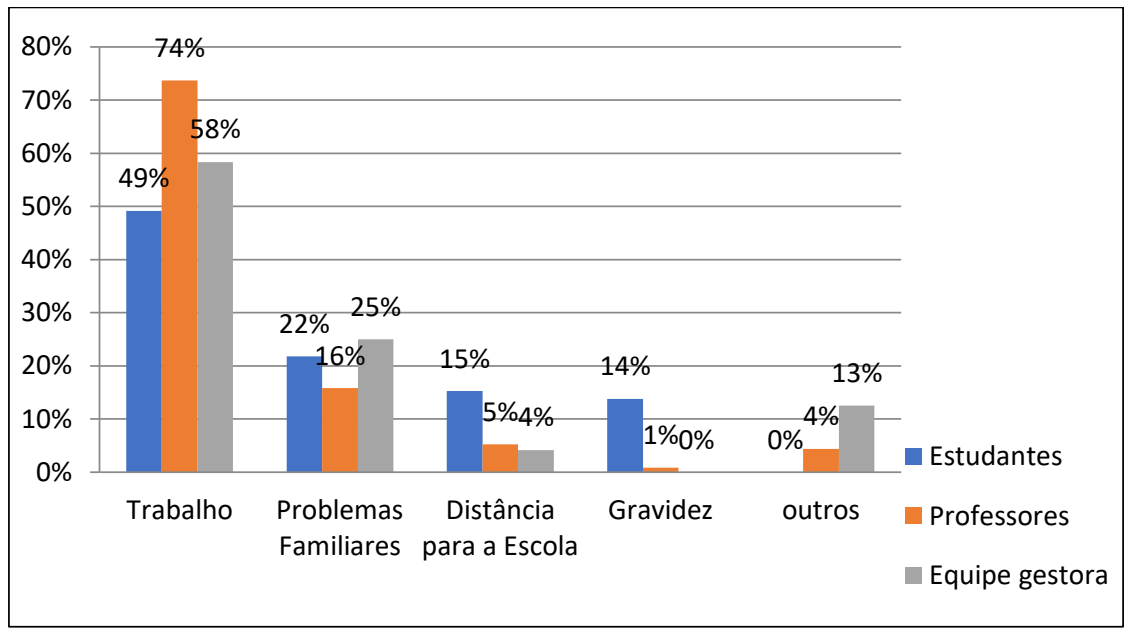

Fonte: Elaborado pelas autoras, pesquisa (2017).

Os problemas familiares foram a segunda razão para o abandono apontado por estudantes (22\%), professores (16\%) e equipe gestora (25\%), seguido pela distância para escola (10\% dos estudantes, $5 \%$ dos professores e $4 \%$ da gestão escolar), e pela gravidez ( $14 \%$ dos estudantes, $1 \%$ dos professores, não sendo sinalizada pela gestão escolar).

É importante considerar que a gravidez pode ser uma razão também incluída nos problemas de família mencionados anteriormente e que envolve vários aspectos que dificultam a permanência, principalmente de mães adolescentes na escola. Sobre esses aspectos, Rodrigues, Silva e Gomes (2019, p. 232) afirmam que: 
O afastamento da adolescente da escola não é algo determinante apenas pela gravidez, mas pode ser decorrente do preconceito dos colegas, da falta de apoio da escola e dos amigos, a vergonha pelas mudanças no corpo e por colocar em evidência a vida da adolescente. Quando um adolescente abandona a escola, está perdendo uma infinidade de oportunidades como, de empregos, de estabilidade de vida financeira e emocional, e, principalmente, de realização pessoal. De fato, todas essas questões contribuem para o insucesso profissional e podem ocasionar frustrações, sentimentos de baixa estima, insatisfação e ausência de perspectiva de vida.

Essas autoras salientam que esses problemas constituem a realidade de adolescentes de baixa renda, já que as famílias dos jovens pais e mães não possuem condições financeiras para arcar com as despesas. Além disso, é preciso entender a forma como o masculino e o feminino se materializam em cada família e impõem interdições, geralmente às mulheres que, por estarem grávidas, terem se casado ou precisarem cuidar de algum parente ou dos filhos, geralmente, são quem, com maior frequência, desistem de estudar.

Os estudantes não indicaram outros aspectos para o abandono escolar, ademais o trabalho, problemas familiares, distância para deslocamento até escola e a gravidez. Já professores (4\%) e equipe gestora (13\%) indicaram outras razões. No conjunto desses outros motivos, encontramos referência ao cansaço devido ao trabalho, dificuldade em conciliar trabalho com os estudos, falta de motivação e de perspectiva do aluno. Sobre a falta de motivação e perspectiva, segundo Arroyo (2007), a falta de um projeto de futuro em longo prazo faz com que o elo do estudante de EJA com a escola fique bastante fragilizado. É exatamente nesse aspecto que o fazer pedagógico deverá conferir a diferença, no sentido de apontar perspectivas, tornar o ambiente escolar atrativo e um local de apoio às dificuldades que aparecem no caminho. Autores como Bartlett $\mathrm{e}$ Macedo (2015) apontam a importância de fortalecimento de laços entre os sujeitos pedagógicos da EJA, estudantes-docentes, estudantes-estudantes. Para tanto, faz-se necessário o 
desenvolvimento de uma prática pedagógica pautada no olhar atento e diferenciado para cada um dos nossos estudantes.

Professores e gestão escolar também indicaram fatores que influenciam a evasão, a maioria dos professores (51\%) e da equipe gestora (75\%) apontou outros fatores (Gráfico 2), dentre esses fatores, foram citados problemas com o transporte escolar, cansaço devido ao trabalho, o horário de saída do trabalho, problemas familiares, insegurança no entorno da escola, o trabalho sazonal (noturno), necessidade de viajar a trabalho e falta de perspectiva do aluno. Também foram elencados aspectos como a falta de um atendimento individualizado por professores (19\%) e pela gestão (13\%). A violência escolar foi apontada por professores (12\%) e pela equipe gestora (8\%), como um aspecto que influencia a evasão escolar na EJA, enquanto que a qualidade da estrutura das escolas e a falta de merenda foram consideradas somente pelos professores, (13\% e 4\%, respectivamente).

Percebe-se que parte da evasão na Educação de Jovens e Adultos pode ser justificada pela necessidade de se trabalhar. Para Silva e Oliveira (2013), a proposta educativa continua representando o trabalhador assalariado como única forma de inserção no capitalismo, desconsiderando as formas concretas de subsistências de seus educandos. Nessas abordagens, os educandos aparecem, não raro, como sujeitos desinteressados. Esse fato pode frustrar o educador, que deseja concluir seu trabalho "sem nenhum" a menos (SILVA; OLIVEIRA, 2013). Arroyo (2007) destaca a instabilidade e a imprevisibilidade do trabalho informal, enfatizando que a luta diária pela sobrevivência dificulta a elaboração de projetos futuros. Segundo o autor, sem os direitos trabalhistas, o educando não possui certos direitos estudantis conferidos pelos estabelecimentos educativos aos estudantes-trabalhadores. Portanto, é importante que o professor que trabalha com alunos da EJA tenha um perfil flexível. Ele deve estar atento às dificuldades de cada um e precisa manter um diálogo constante para facilitar a organização e o bom entendimento entre todos na sala de aula (SOARES, 2007).

Cabe destacar que a maior parte das razões apontadas pelos três grupos de sujeitos pesquisados para a interrupção da vida escolar dos estudantes da EJA pode ser englobada em aspectos 
externos à escola, sendo eles: trabalho, problemas familiares (casamento, gravidez, divórcio, problemas de saúde na família, entre outros). Mesmo quando o instrumental direcionado aos docentes e à equipe gestora solicita a indicação de elementos escolares que levam a evasão escolar na EJA, os docentes e os gestores pesquisados, indicaram como a segunda causa, depois do trabalho a resposta "outros". No âmbito dessa resposta, foram principalmente encontradas referência ao transporte escolar, cansaço devido ao trabalho, tempo de afastamento escolar, dificuldade em conciliar trabalho com os estudos, horário de saída do trabalho, problemas familiares, falta de interesse, insegurança em torno da escola, distância entre a casa e o trabalho, o trabalho sazonal (noturno), necessidade de viajar a trabalho e falta de perspectiva do aluno.

Gráfico 2. Aspectos que influenciam a evasão escolar, na visão de docentes e gestores

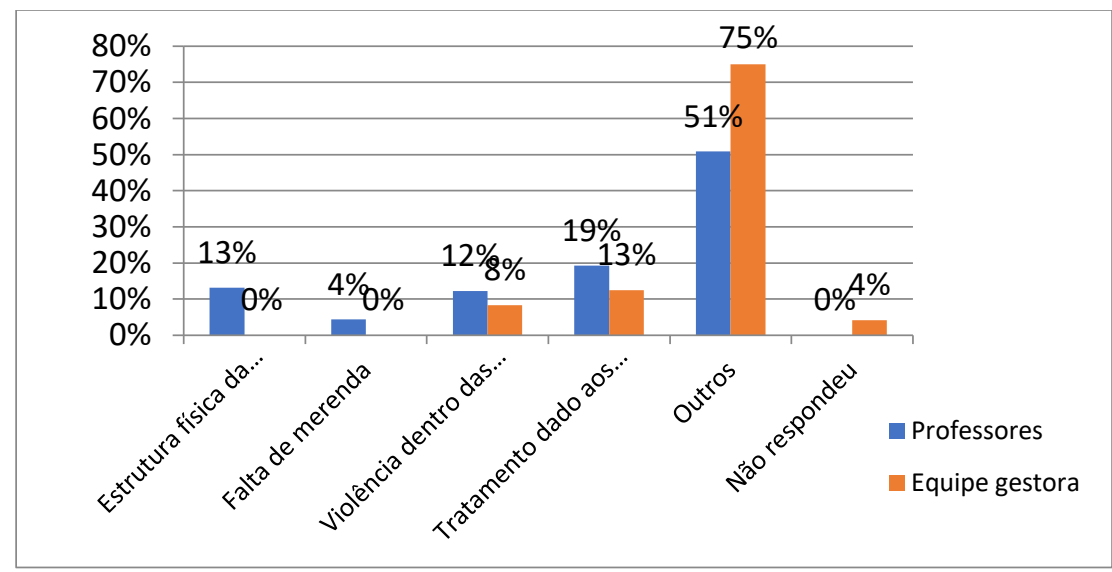

Fonte: Elaborado pelas autoras, pesquisa (2017).

Esse dado remete à necessidade de que as intervenções para promoção de permanência escolar na EJA passem necessariamente pela articulação com outras dimensões além da didático-pedagógica, incluindo a interface com outras gerências no âmbito da Secretaria Estadual de Educação e outras Secretarias Estaduais, no que se refere, por exemplo, às questões de transporte escolar, empoderamento da mulher, criação de oportunidades de trabalho/remuneração com dignidade assegurada. As ações intersetoriais, ao serem 
desenvolvidas, possibilitam a compreensão da evasão como fenômeno múltiplo e multifacetado (SILVA; PASSOS, 2018) e, dessa forma, contribuem para garantir a permanência do estudante na escola.

A escola e outros tipos de educação não formal parecem estar relacionados à inserção no mundo do trabalho. Contraditoriamente, o trabalho, que num primeiro momento representa um obstáculo aos estudos, em virtude da dificuldade para conciliação de estudos e trabalho, acaba por representar, no futuro próximo, o motivo para retomada dos estudos em função da necessidade de melhor qualificação profissional. Sendo assim, a escola é compreendida ora como o espaço de aprendizado e como um lócus do saber, ajudando o estudante a ler o mundo; e ora em uma abordagem tecnicista, que entende a escola como um espaço de preparação para o mercado de trabalho, ora espaço para o desenvolvimento das competências conceito bastante empregado nos meados da década de 1990 (PERRENOUD, 2000).

A relação entre trabalho, família e educação mostra-se complexa e esses elementos são interdependentes. A escola, nesse contexto, aparece como um espaço plural, que abarca o sonho de melhorar de vida e também o desejo de conhecer e de melhor ler o mundo. Por outro lado, mostra-se também como um espaço de tensão e de luta para a conquista dos objetivos que estão postos em pauta. Nesse sentido, a relação pessoal entre professores e alunos pode tanto motivá-los a continuar os estudos, como se configurar como um impeditivo para continuidade do processo de escolarização.

\section{Sobre a retomada aos estudos}

Quanto às razões para retomar os estudos (Gráfico 3), inicialmente os participantes foram questionados acerca dos motivos para os estudantes estarem matriculados na modalidade. Estudantes (53\%), professores (33\%) equipe gestora (36\%) elegeram principalmente o desejo de concluir os estudos de forma mais rápida. Na sequência, a distorção idade/série, foi indicada por estudantes (17\%), professores (42\%) e equipe gestora (52\%). O enfrentamento 
de situações de reprovação também foi apontado por estudantes (17\%) e professores (2\%). Para $17 \%$ dos professores, o que conduz à matrícula na EJA é a oferta exclusiva da modalidade no período noturno, assim como, para gestão (8\%) e estudantes (5\%). Estudantes (10\%), professores (5\%) e equipe gestora (4\%) indicaram outros aspectos.

Ainda sobre as razões para a matrícula na modalidade, docentes e equipe gestora consideraram que o principal motivo é a distorção idade/série, seguida do desejo de conclusão dos estudos de maneira mais rápida. Já as situações de reprovações foram sinalizadas de modo incipiente, quando comparadas às respostas dos estudantes. Do nosso ponto de vista, assumir que as situações de reprovações, de certa forma, conduziram os estudantes à Modalidade, parece gerar desconforto aos educadores que fazem o sistema de ensino e, por assim dizer, partilham do passado de "fracasso escolar" com esses indivíduos.

Gráfico 3: Razões de matrícula na modalidade indicada por estudantes, professores e equipe gestora

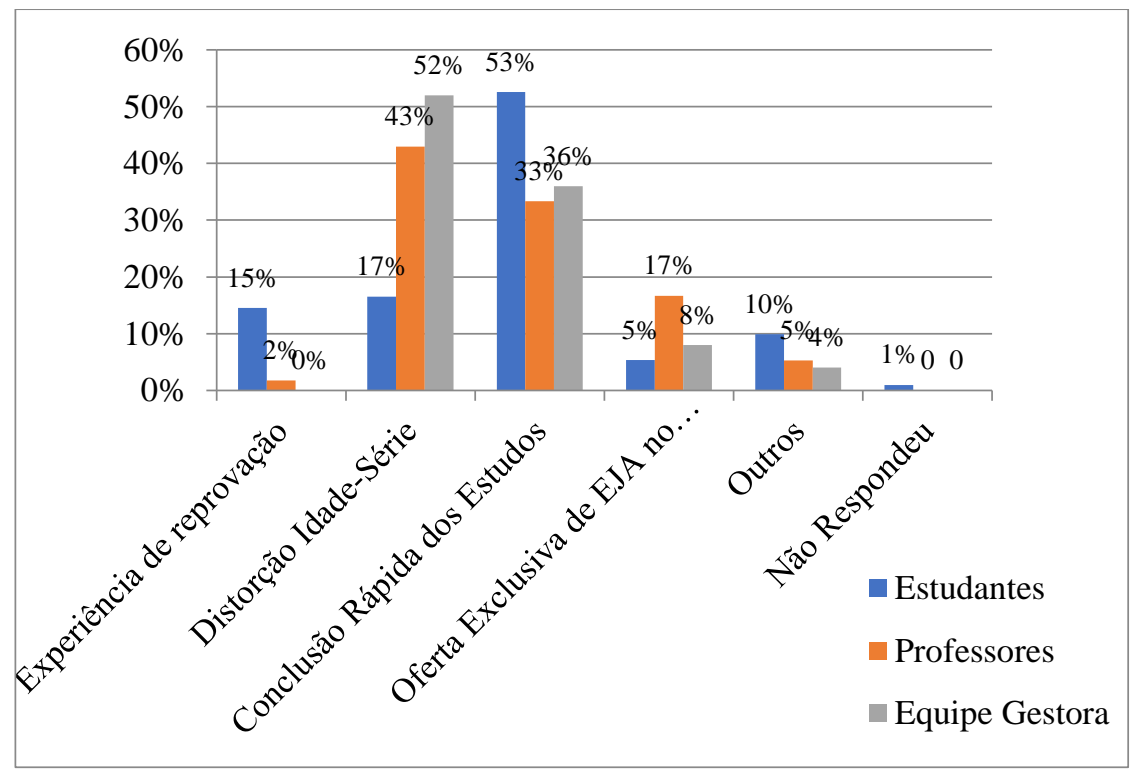

Fonte: Elaborado pelas autoras, pesquisa (2017). 
Silva e Freitas (2014), que realizaram um estudo sobre as histórias de escolarização e concepções dos sujeitos da EJA, destacam que o caminho de escolaridade anterior à EJA é marcado por muitas dificuldades, tanto pelas opções que tiveram de fazer pelo trabalho, em detrimento do estudo, quanto pela ausência ou distância das escolas de suas residências. "No entanto, a EJA apresenta-se como a única possibilidade de continuarem estudando, tanto pelo seu funcionamento no horário noturno, embora enfrentem uma luta contra o cansaço, como por funcionar em escolas públicas que permitem o acesso de todos." (p.9). Isso aumenta a responsabilidade da escola, no sentido de garantir a permanência e conclusão dos estudos desses estudantes, que já vivenciaram "o fracasso escolar".

Sobre os motivos de retorno aos estudos (Gráfico 4), os estudantes sinalizaram em primeiro lugar a exigência do mercado de trabalho (27\%), seguida da necessidade de concluir os estudos (24\%), satisfação pessoal (11) e a obtenção de conhecimento (9\%) e outros (7\%). Interessante destacar que a principal razão de abandono da vida escolar indicada pelos pesquisados é também a mesma para o retorno, ou seja, o trabalho. Nas falas dos estudantes aparecem exigências de escolarização impostas pelo mercado de trabalho e o desejo por uma elevação na qualidade de vida.

Gráfico 4: Razões para o retorno aos estudos, indicadas por estudantes

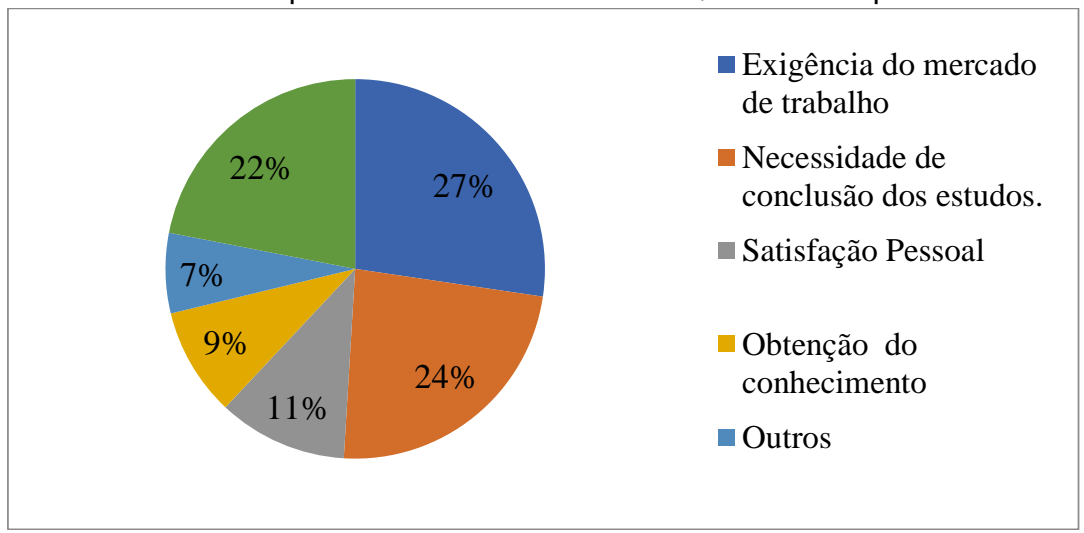

Fonte: Elaborado pelas autoras, pesquisa (2017).

${ }^{3}$ Charlot, B. Da relação com o saber: elementos para uma teoria. Tradução Bruno Magne. Porto Alegre: Artes Médicas Sul, 2000. 
Para Santana (1996), os alunos buscam a escolarização devido às próprias exigências impostas pelo mundo letrado e acreditam que, dominando as habilidades de ler e escrever, poderão conquistar sua independência. Por outro lado, Bernardim (2006) afirma ser esse um motivo de preocupação, visto que o critério de decisão para matrícula na EJA, entre os jovens, efetiva-se por motivos que vêm a desmerecer a EJA, conforme se observa na resposta, da maioria dos alunos, que declara ter optado pela EJA pela "rapidez" na conclusão. Ainda de acordo com o autor, a migração de estudantes que abandonam o Ensino Regular para ingressarem na EJA se apresenta como possibilidade de pesquisa, pois os desdobramentos que esse fenômeno pode apresentar na conformação da educação escolar ao longo dos anos, apresentam-se como campo importante de análise e de discussão.

\section{Razões para a permanência escolar}

Sobre os fatores que mais contribuem para a permanência do estudante na escola (Gráfico 5), o apoio familiar (29\%) e aulas mais atrativas (27\%) configuraram os mais recorrentemente citados, seguidos por trabalho (21\%) e proximidade da escola da residência (16\%). Como se pode perceber, os aspectos envolvidos na evasão escolar também são considerados como cruciais para colaborar com a permanência escolar na EJA, como os problemas familiares e questões relativas ao trabalho e à necessidade de se obter o sustento para frequência na escola. É importante entender o contexto em que o estudante está inserido e a complexidade de relações e efeitos que dali emanam. 
Gráfico 5: Razões para permanência escolar, segundo os estudantes da EJA

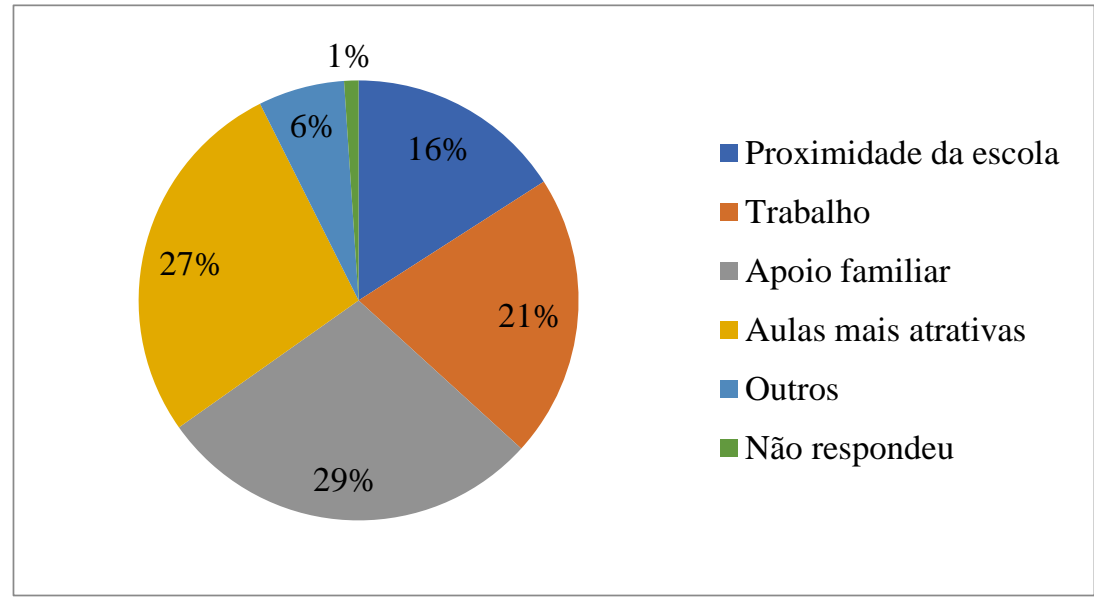

Fonte: Elaborado pelas autoras, pesquisa (2017).

Os professores foram questionados sobre os aspectos do planejamento que podem contribuir para a diminuição da evasão na EJA (Gráfico 6). A maior parte dos professores (36\%) afirmou que, em relação a sua prática docente, a adequação do perfil das aulas ao do estudante é primordial para sua permanência na modalidade, (35\%) consideraram importante direcionar o planejamento voltado à necessidade da EJA, (15\%) indicaram como relevante propostas em conjunto com outras disciplinas, (11\%) avaliaram que o seu planejamento docente pode contribuir para permanência escolar, ao incluir a identificação das dificuldades de aprendizagem dos estudantes e (4\%) responderam outros aspectos, que não esses mencionados na questão elaborada. 
Gráfico 6: Aspectos do planejamento que podem contribuir para a diminuição da evasão na EJA indicada pelos professores

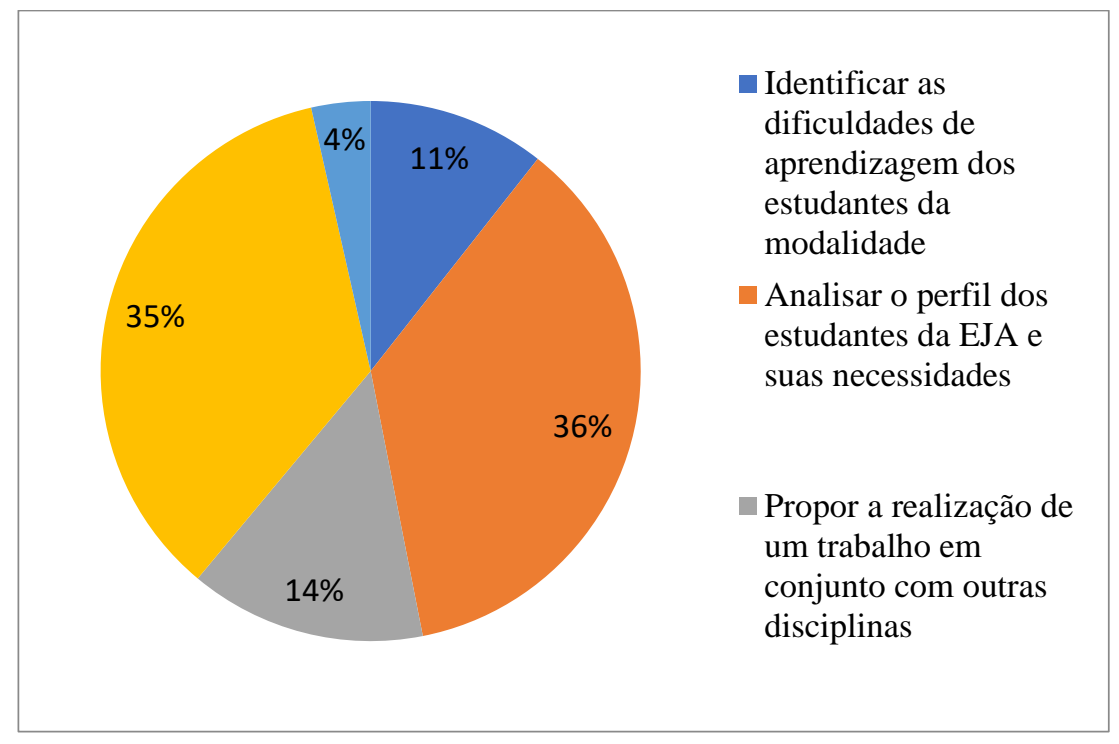

Fonte: Elaborado pelas autoras, pesquisa (2017).

Quanto à prática docente e a permanência dos estudantes (Gráfico 7), os gestores apontaram como aspectos importantes a organização de aulas criativas (34\%), a adequação ao perfil do estudante da EJA (27\%), a realização de ações que valorizem os estudantes (23\%), a realização de projetos pedagógicos (8\%), e outros motivos (8\%). 
Gráfico 7: Aspectos do planejamento que podem contribuir para permanência dos estudantes, indicados pelos professores

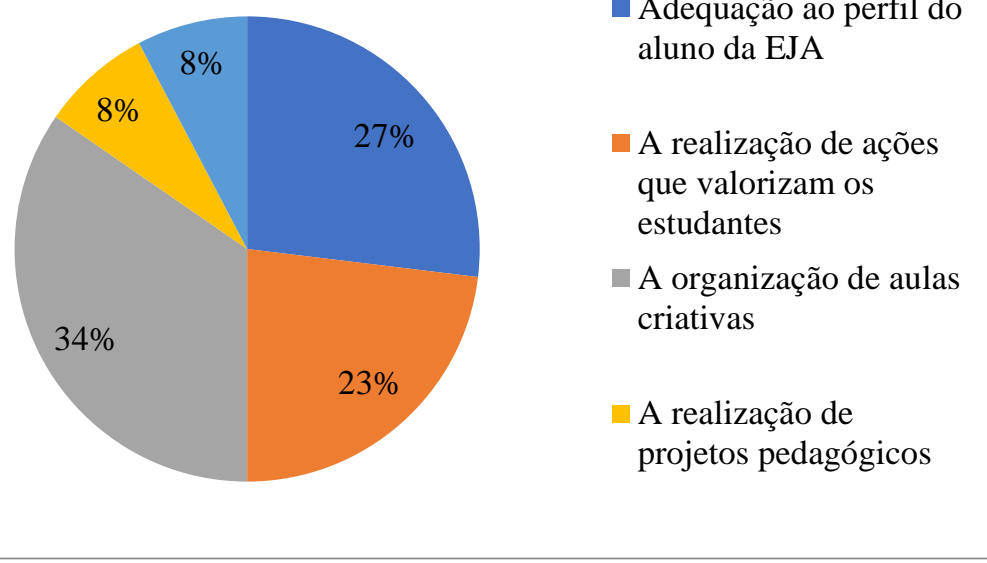

Fonte: Elaborado pelas autoras, pesquisa (2017).

A Educação de Jovens e Adultos, de acordo com a lei 9394/96, é uma modalidade da educação básica com especificidades próprias que deve, por isso, receber um tratamento consequente. Para tanto, além das adequações curriculares que orientam o que ensinar, devese também levar em conta como ensinar (SANTOS 2003). Para que se possa pensar o planejamento e avaliação em Educação de Jovens e Adultos, reconstruindo-os a partir de seus sujeitos e com eles, é importante a análise de como se vem construindo, quais suas raízes e quais as implicações decorrentes das opções teóricas assumidas (HOFFMANN, 2009).

O planejamento é um meio para programar as ações docentes, mas é também um momento de pesquisa e reflexão intimamente ligado à avaliação. Corroborando com esse entendimento, Hoffmann (2009) destaca que o ato de planejar possui diferentes dimensões e, por conseguinte, não se trata de uma ação desvinculada da realidade social, política e pedagógica vivenciadas no cotidiano da escola. Sousa e França (2013), em seu trabalho sobre o planejamento realizado no cotidiano dos professores do Programa Nacional de Inclusão de Jovens - PROJOVEM Urbano, evidencia que as questões teóricas desenvolvidas no contexto educacional 
brasileiro parecem ser reivindicadas, mesmo que de forma inconsciente pelos professores. Para a autora, o entendimento de questões básicas do processo de ensino deve ser retomado.

Há uma expressiva concordância entre professores brasileiros de que a formação docente deverá acontecer, buscando-se o papel ativo do professor que, através da reflexão, adquirirá conhecimento crítico de sua ação docente, podendo reconstruir os condicionantes de sua ação, os pressupostos de suas escolhas cotidianas. É considerando esse pressuposto que a Secretaria de Educação, por meio da GEJAI - Gerência de Educação de Jovens, Adultos e Idosos, vem oferecendo formações pedagógicas, objetivando fomentar a interação entre os professores da EJA, bem como propiciar a discussão dos princípios e práticas que norteiam suas atuações pedagógicas, de modo a aprimorá-las.

As práticas pedagógicas da EJA precisam ser comprometidas em promover a leitura de mundo, estabelecendo diálogos com as realidades e saberes dos educandos, a partir de uma educação dialógica, problematizadora e emancipatória (FREIRE, 2016). À vista disso, Freitas e Cavalcante (2021), ao apresentarem uma reflexão sobre o ensino de Leitura da/na Educação de Jovens e Adultos (EJA), discutem que uma significativa parcela dos sujeitos da EJA são vítimas da indiferença, do desemprego e do descaso, socialmente estigmatizados e excluídos, muitas vezes, vítimas ou envolvidos em casos de violência. Por isso, a modalidade precisa ser reconhecida como espaço de diversidades, entre os sujeitos sociais, que abriga cenários em que vivência e aprendizagem são construídas. As diversidades culturais dos/das estudantes apresentam características singulares, entre elas: múltiplas opções religiosas, variedades linguísticas, expectativas socioculturais.

Nesse sentido, a prática pedagógica do professor é basilar, haja vista estes estudantes procuram no professor um ensinamento que promova a autoestima, que os levem a construir seus próprios saberes, na articulação com seus propósitos, em busca da sua efetiva participação na sociedade (FRANÇA, 2015). Outro aspecto importante é o comprometimento da gestão, o que reflete no comprometimento dos professores com os alunos e destes com a escola, com o seu próprio percurso formativo. O corpo docente, das escolas com oferta 
de EJA, em horário noturno, deve contar com presença da gestão escolar, durante a noite, da mesma forma, que nos demais turnos escolares (FARIA, 2013).

Em relação às ações, que a gestão escolar pode promover para a permanência dos estudantes da EJA na escola, as repostas dos gestores foram as seguintes: apoiar as atividades da modalidade (33\%), desenvolver ações do interesse dos estudantes da EJA (29\%), ouvir as reivindicações dos estudantes (13\%), melhorar as relações interpessoais (13\%) e outros (12\%).

Quanto aos aspectos que podem contribuir para a permanência de estudantes da EJA, segundo eles mesmos, as aulas mais atrativas e o apoio familiar foram os considerados mais importantes. Já os professores apontam como relevante analisar as necessidades deles na hora do planejamento didático, bem como adequar as aulas ao seu perfil. Os gestores também apontam a adequação das aulas ao perfil dos estudantes como primordial e, além disso, acreditam que a gestão escolar pode promover a permanência dos estudantes da EJA na escola, apoiando as atividades da modalidade. Diante dessa percepção de docentes e gestores, é importante ressaltar a necessidade de um processo permanente de formação para professores da EJA, que possibilite compreender as especificidades da modalidade e refletir sobre sua prática pedagógica. Nessa direção, Melo (2015, p. 18335) afirma que:

É necessário também pensar na institucionalização de práticas de EJA presentes numa pedagogia que tenha concretude a partir da união entre teoria e prática e da relação simbiótica entre ensino, pesquisa e extensão, possibilitando a transformação e o redimensionamento dos saberes populares, construídos na lógica do saber das experiências de vida dos sujeitos da EJA, como força motriz das práticas pedagógicas. Isto deve ser ponto de pauta da formação docente, num esforço recorrente de criar um corpo de saberes práticos e teóricos possíveis de se constituir em fundamentos que alimentem a formação inicial e continuada dos educadores desta modalidade. 
Levando em conta que o trabalho é um fator tão importante, envolvido no processo de evasão escolar na EJA, no que diz respeito à sua conciliação, com os estudos, os resultados demonstraram que a maioria dos pesquisados estudam à noite por trabalharem durante o dia (75\%), enquanto um número expressivo de estudantes, afirma não ter problemas para conciliar trabalho e estudo (22\%) (gráfico 8). Esse último dado pode estar relacionado ao processo de juvenilização da modalidade, contrapondo-se a estudos anteriores que caracterizavam o perfil de estudantes da EJA, como pessoas jovens e adultas, vivendo no mundo adulto do trabalho e que possuem responsabilidades sociais e familiares (ARROYO, 2007; SILVA; FREITAS, 2014). Além disso, esses dados reforçam a importância da escola estar ciente das dificuldades que esses estudantes enfrentam para prosseguirem os estudos, fazendo-se necessária a busca de estratégias que contribuam para conciliar os estudos com a vida pessoal e profissional deles, diminuindo os índices de evasão.

Gráfico 8: Conciliação entre trabalho e estudo

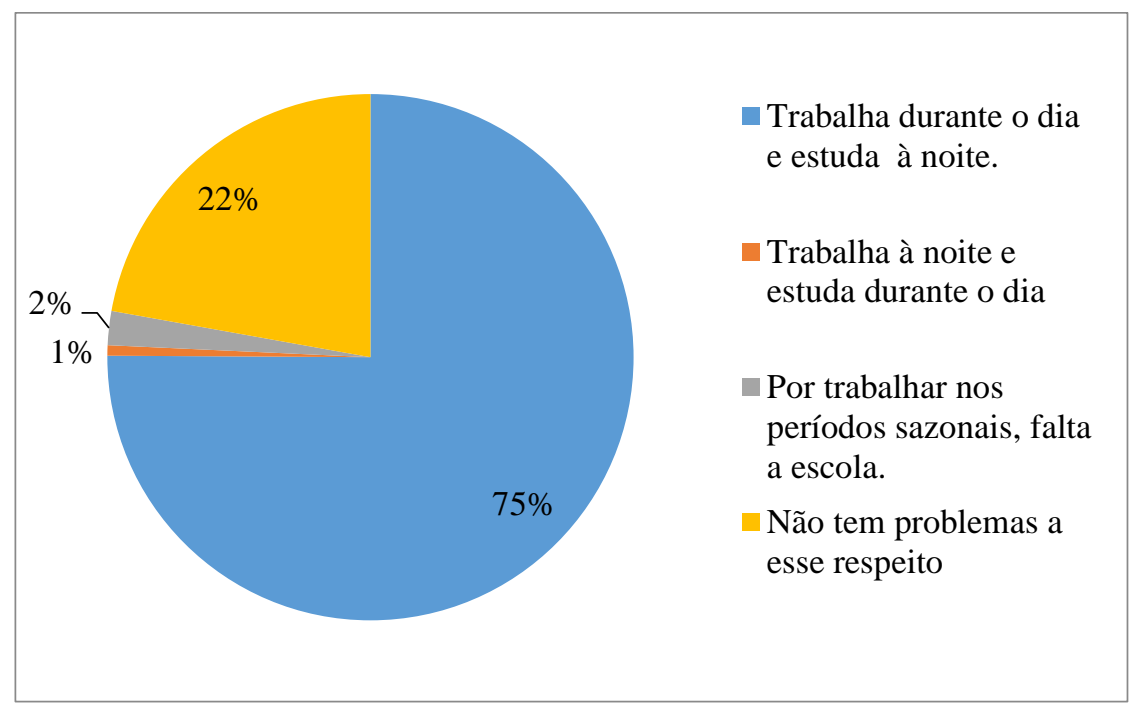

Fonte: Elaborado pelas autoras, pesquisa (2017). 


\section{AÇÕES QUE VISAM REDUZIR A EVASÃO ESCOLAR NA EJA}

A Gerência de Educação de Jovens, Adultos e Idosos vem desenvolvendo ações formativas para professores sobre a evasão na EJA, desde 2014, alinhadas aos preceitos da pesquisa participante, considerando a escola, como lócus de produção de conhecimento. Nessa direção, nos momentos formativos são compartilhados e discutidos os resultados da pesquisa sobre evasão escolar na EJA, além de serem realizados estudos de textos sobre o tema e a socialização das experiências desenvolvidas pelas escolas.

Nesses encontros, os professores ressaltaram ter clareza dos impactos que a evasão acarreta à escola, reconhecendo a necessidade de ações, de enfrentamento. Logo, as escolas elaboraram um cronograma de atividades, consideradas como atrativas e instigantes para a comunidade escolar. Ademais, a cada encontro formativo, aconteceu uma sistematização dessas atividades, propiciando um espaço para troca de experiências. A seguir, serão descritas ações que estão sendo realizadas nas e pelas unidades escolares, com a finalidade de diminuir os índices de evasão na EJA.

Desenvolvimento de monitoria - No CEJA Maria da Conceição Cisneiros Sampaio, foi realizado um projeto de monitoria que consiste em designar um grupo de alunos para entrar em contato com os colegas da turma que apresentarem número significativo de faltas consecutivas. Acredita-se que, ao atribuir essas tarefas aos estudantes, o professor os estimula a assumirem responsabilidades, fortalecendo o espírito de equipe, e a se tornarem protagonistas do processo de enfrentamento da evasão.

Evento de acolhimento - As Escolas Central de Barreiros, Seráfico Ricardo e Dom Juvêncio investem no acolhimento no início do ano e do semestre. As ações visam promover a integração entre estudantes e professores.

Aulas Interdisciplinares - Os professores da escola Dom Juvêncio realizaram o planejamento das aulas em conjunto e as ministraram em duplas, evidenciando diferentes perspectivas sobre a mesma temática, em uma dinâmica diferenciada.

Atividades Culturais - A Escola Professora Amélia Coelho desenvolveu um projeto denominado CINEJA que consiste numa 
mostra de filmes com temáticas variadas, desde obras clássicas do cinema a filmes motivacionais.

Desenvolvimento profissional e pessoal - Buscando trazer a temática do trabalho para a aula, a escola Senador Petrônio Portela desenvolveu uma feira de profissões, na qual os professores organizaram uma exposição sobre as atividades que os estudantes desempenhavam, apresentando suas habilidades profissionais, como forma de valorizar os diversos saberes. Também foram convidadas instituições de educação técnica ou superior, e outros profissionais para participarem da exposição. A mesma unidade escolar realizou o projeto "Ex-aluno contando suas experiências", nele, os estudantes egressos foram convidados a compartilhar suas experiências, evidenciando a contribuição dos estudos no seu desenvolvimento pessoal e profissional, como também as dificuldades enfrentadas.

\section{CONSIDERAÇÕES FINAIS}

Este trabalho reúne dados para um diagnóstico sobre a evasão escolar na EJA, bem como as ações didático-pedagógicas vivenciadas nas unidades escolares para a prevenção da evasão na Rede Estadual de Ensino de Pernambuco. Entre os achados, destacase que os aspectos externos das escolas são mais determinantes do que os internos como causa do abandono da vida escolar dos estudantes da EJA.

O trabalho de pesquisa aqui empreendido proporcionou uma aproximação, no sentido de compreender o fenômeno da evasão escolar na EJA da Rede de Ensino. Desse modo, os procedimentos de pesquisa desenvolvidos se alinham com o conceito de pesquisa-ação, na qual, os sujeitos participantes são ao mesmo tempo coautores das intervenções aqui descritas. Haja vista, um dos primeiros desafios que se coloca em termos do desenvolvimento deste estudo é a necessidade de ampliação do número de escolas participantes, levando em conta que a pesquisa prevê um trabalho coletivo entre a Secretaria Estadual de educação, Regionais de Educação e as unidades escolares. Isso porque as ações de enfrentamento precisam ser delineadas a partir do perfil de estudantes e das especificidades de cada unidade escolar. 
No bojo dos aspectos internos à escola, foram pontuados pelos sujeitos da pesquisa principalmente a necessidade de que as aulas sejam mais dinâmicas e que o perfil dos estudantes seja levado em consideração no planejamento didático. Além disso, alguns aspectos do âmbito da gestão escolar, como a presença efetiva dos gestores escolares, no período noturno e a promoção de ações para o fortalecimento e visibilidade da modalidade na comunidade escolar.

Ao longo do trabalho, algumas questões ganharam relevo e carecem serem esclarecidas, dentre elas destacamos a necessidade de uma reflexão mais profunda sobre as relações estabelecidas entre a evasão escolar na EJA e gênero, em face dos problemas apontados quanto à gravidez, e as situações de subordinação, no âmbito das relações conjugais.

Vislumbra-se também como horizonte para o grupo de pesquisa de evasão na EJA, a análise comparativa a partir das ações de prevenção e enfretamento, em termos do impacto nos índices de evasão escolar na Rede. Para tanto, salientamos a necessidade de políticas afirmativas, já que o fenômeno da evasão escolar na EJA aqui investigado demanda o desenvolvimento de políticas de intersetorialidade, contemplando, por exemplo, o transporte escolar, os direitos humanos, empoderamento da mulher, a geração de trabalho e renda em condições de dignidade. Para concluir, reiteramos que a Secretaria Estadual de Educação deverá ser o agente interlocutor no diálogo com outras instâncias no sentido de garantir o direito à educação aos jovens, adultos e idosos na modalidade.

\section{REFERÊNCIAS}

ARROYO, M. Balanço da EJA: o que mudou nos modos de vida dos jovens-adultos populares? REVEJ@: Revista de Educação de Jovens e Adultos, v. 1, p. 1-18, 2007.

BARTLETT, L.; MACEDO, M.S.A. N. Aproximações entre a Concepção de Alfabetização de Paulo Freire e os Novos Estudos do Letramento. Revista Brasileira de Alfabetização - ABALF. Vitória, ES. v. 1, n.1, p. 227-236, 2015. 
BERNARDIM, M. L. Da Escolaridade Tardia à Educação Necessária: Estudo das Contradições na EJA em Guarapuava-Pr. Dissertação (Mestrado em Educação) - Universidade Federal do Paraná, Curitiba, 2006.

BORJA, I. M. F. S.; MARTINS, A. M. O.; Evasão escolar: desigualdade e exclusão social. Revista Liberato, v. 15, n. 23, p. 93-102, 2014.

BRASIL. Constituição da República Federativa do Brasil de 1988.

Presidência da República Casa Civil - subchefias para assuntos jurídicos, 1988. Disponível em:

http://www.planalto.gov.br//ccivil_03/Constituiçao/ConstituiçaoCom pilado. Acesso em: 23 ago. 2021

BRASIL. Lei n 9.394, 20 de dezembro de1996. Estabelece as diretrizes e bases da Educação Nacional, Diário Oficial da União, Brasília, DF, 23 dez. 1996. Disponível em:

http://www.planalto.gov.br/ccivil_03/LEIS/L9394.htm. Acesso em: 12 ago. 2021.

BRASIL. Resolução CEB/CNE nº 3 de 15/06/2010. Institui Diretrizes Operacionais para a Educação de Jovens e Adultos nos aspectos relativos à duração dos cursos e idade mínima para ingresso nos cursos de EJA; idade mínima e certificação nos exames de EJA; e Educação de Jovens e Adultos desenvolvida por meio da Educação a Distância. Diário Oficial da União, Brasília, DF, 16 jun. 2010.

Disponível em: https://www.normasbrasil.com.br/norma/?id=113429. Acesso em: 10. ago. 2021.

BRANCO, E. P. et al. A evasão escolar e as consequências na formação humana. In: Congresso Internacional de Educação da Unoeste, Presidente Prudente. Anais [...] Presidente Prudente, SP: Universidade do Oeste Paulista, 2019. p. 78-89.

Charlot, B. Da relação com o saber: elementos para uma teoria. Tradução Bruno Magne. Porto Alegre: Artes Médicas Sul, 2000.

DORE, R.; SALES, P. E. N.; CASTRO, T. L. Evasão nos cursos técnicos de nível médio da rede federal de educação profissional de Minas Gerais. In: DORE, R.; ARAÚJO, A. C.; MENDES, J. S. (Orgs.). Evasão na 
educação: estudos, políticas e propostas de enfrentamento. Brasília, DF: Instituto Federal de Brasília, 2014. p. 379-413.

FALCÃO, J. T. R.; RÉGNIER, J. Sobre os métodos quantitativos na pesquisa em ciências humanas: riscos e benefícios para o pesquisador. Revista Brasileira de Estudos Pedagógicos, v. 81, n. 198, p. 229-243, 2000.

FARIA, R. S. Evasão e permanência na EJA: Por um trabalho de qualidade na gestão de uma escola da Rede Municipal de Belo Horizonte. Dissertação de Mestrado. Juiz de Fora: Faculdade de Educação, Universidade Federal de Juiz de Fora, 2013.

FRANÇA, L.A.L. Evasão escolar na Educação de Jovens e Adultos. Monografia (Conclusão de graduação). Pará de Minas: Faculdade de Pará de Minas, 2015.

FREIRE, Paulo. Pedagogia da Autonomia: saberes necessários à prática educativa. São Paulo: Paz \& Terra, 2016.

FREITAS, M. L. Q.; CAVALCANTE; V. C. C. Mediações didáticas em uma aula de leitura na EJA - mulheres relendo suas realidades e o mundo. Educação, v. 46, 2021.

GIL, Antônio Carlos. Como elaborar projetos de pesquisa. São Paulo. Atlas. 1991.

HOFFMANN, J. EJA: Planejamento, metodologias e avaliação. Rio Grande do Sul: Mediação, 2009.

MELO, F. S. Formação de professores e prática docente na EJA: saberes conceituais, metodológicos e políticos. In: Anais do XII Congresso Nacional de Educação: Formação de Professores, Complexidade e Trabalho Docente. GT 13: Educação de Jovens e Adultos. Curitiba-PR, 2015.

PERNAMBUCO. Diretrizes Operacionais para a Oferta da Educação de Jovens e Adultos. Secretaria Executiva de Desenvolvimento da Educação - SEDE. Gerência de Políticas Educacionais de Jovens, Adultos e Idosos. 2016. Disponível em: http://www.educacao.pe.gov.br/portal/?pag=1\&men=177. Acesso em: 13 ago. 2021. 
PERNAMBUCO. Sistema de Informações da Educação de

Pernambuco - SIEPE. Governo do Estado. 2017. Disponível em https://www.siepe.educacao.pe.gov.br/. Acesso em: 13 ago. 2021.

PERRENOUD, P. "Construir Competências é Virar as Costas aos Saberes?" In: Revista Pátio, Porto Alegre: ARTMED, v. 03, n. 1, p. 1519. 2000.

RODRIGUES, S.R.; SILVA, M.V.O.; GOMES, M.A.V. Gravidez na Adolescência: suas implicações na adolescência, na família e na escola. Educação e Emancipação, São Luís, v. 12, n. 2, p. 228-252, 2019.

SANTANA, L. Usos e funções da leitura e da escrita para analfabetos e recém-alfabetizados. Dissertação (Mestrado em Educação) - Universidade Federal de Minas Gerais, Belo Horizonte. 1996.

SANTOS, G. L. Quando adultos voltam para a escola: $\mathbf{O}$ delicado equilíbrio para obter êxito na tentativa de elevação da escolaridade. In: SOARES, Leôncio (Org.). Aprendendo com a diferença - Estudos e Pesquisas em Educação de Jovens e Adultos. Belo Horizonte, MG: Autêntica, 2003, p.11-38.

SILVA FILHO, R. B.; ARAÚJO, R. M. L. Evasão e abandono escolar na educação básica no Brasil: fatores, causas e possíveis consequências. Educação Por Escrito, Porto Alegre, v. 8, n. 1, p. 35-48, 2017. https://doi.org/10.15448/2179-8435.2017.1.24527

SILVA, J. A.; OLIVEIRA, H.S. O Mundo do trabalho e os/as e Educandos/as da Educação de Jovens e Adultos-EJA: "É possível ter segurança nesse emaranhado de formas de viver?" Revista Lugares de Educação [RLE], Bananeiras/PB, v. 3, n.5, p. 143-161. 2013

SILVA, L. G.; FREITAS, M. L. Q. Sujeitos alunos da EJA em Maceió: perfil e histórias de escolarização. Educon, Aracaju, v. 8, n. 1, p.9-12, 2014.

SILVA, M.M. C. L. PASSOS, G. O. O Programa Bolsa Família e as condicionalidades educacionais: análise sobre os resultados da intersetorialidade no Município de Teresina. Revista Educação e Emancipação, São Luís, v. 11, n. 1, p11-35, 2018. 
SOARES, M. A. F. Perfil do aluno da EJA/ Médio na Escola Dr.

Alfredo Pessoa de Lima. 2007. Monografia de Pós-Graduação Universidade Federal da Paraíba, Bananeiras. 2007.

SOUSA, A. S.; FRANÇA, R. N. A Organização Pedagógica do Projovem Urbano: Os (Des) Caminhos do planejamento. In: Anais do II Colóquio Nacional - A Produção do conhecimento em Educação Profissional. Natal: IFRN, 2013.

Submetido em: Julho/ 2021.

Aceito em: Agosto/ 2021. 